\title{
Educação, consenso que merece atenção
}

Resumo: O educomunicador Fernando Rossetti, cofundador de projetos como Cidade Escola Aprendiz e a Rede CEP, em São Paulo, fala sobre o aumento do interesse dos setores governamentais e privados em Educomunicação. Comenta ainda a maneira, por vezes contraditória, pela qual a própria escola ainda lida com a área, assim como os efeitos do aumento do número de iniciativas em Educomunicação junto aos jovens e aos setores educacional e de investimento social privado.

Palavras-chave: Educomunicação, escola, mídias, políticas públicas, investimento social privado.
Abstract: The educommunicator Fernando Rossetti, co-founder of projects with the $\mathrm{Ci}$ dade Escola Aprendiz [City School Apprentice] and Rede CEP [CEP Network], in Sao Paulo, talks on the increase of interest on Educommunication by public and private sectors. He comments the way, sometimes contradictory, by which school itself deals with the area, as well the effects of the rise in the number of educommunication initiatives on youngs and educational and social private investments sectors.

Keywords: Educommunication, school, media, public policies, social private investment.

Desde os tempos de jornalista na Folha de S Paulo até hoje, quando se dedica a fomentar o investimento social dentro da área empresarial, algo em comum pontua o trabalho do cientista social Fernando Rossetti: a visão interdisciplinar em comunicação e educação, utilizada para conscientizar e despertar cidadania. Em suas andanças pelo mundo desde a infância, quando cursou o Ensino Fundamental no Reino Unido, passando pelo período em que trabalhou como repórter internacional de Educação da Folha - e vivenciou a realidade de países tão diversos como Estados Unidos e Joanesburgo -, desenvolveu uma forma também abrangente de enxergar o Brasil. "A nossa cultura é muito aberta a mudanças. Ela agora está começando a se consolidar mais, mas temos muito jogo de cintura em todos os sentidos. Por isso, acho que no Brasil conseguimos misturar temas, e isso é a Educom: a mistura de campos diferentes, dois temas juntos. Pela nossa cultura, lidamos melhor com as contradições do que com culturas mais estabelecidas, como a europeia e americana. Acho que a força que o Brasil tem no mundo, hoje, se deve muito a isso. A gente consegue pensar fora da caixa, como se diz, e criar mais." A seguir, ele fala sobre como esse potencial criativo e de trabalho está ajudando a consolidar a união entre Comunicação Ẽ Educação no Brasil.

Por Juliana Winkel Marques dos Santos* e Vania de Toledo Piza**

\section{C\&E: Como teve início sua trajetória com a Educomunicação?}

Fernando Rossetti: Meu contato com a Educomunicação se aprofundou a partir de meu trabalho como repórter da Folha de S. Paulo, entre 1990 e 1999.

Recebido: 15.06.2011

Aprovado: 04.07.2011

* Jornalista, especialista em Gestão da Comunicação pela Escola de Comunicações e Artes da Universidade de São Paulo.

** É especialista em Marketing de Serviços pela Faculdade de Economia, Administração e Contabilidade da Universidade de São Paulo - FEA, Coordenadora do Curso de Propaganda e Marketing da Universidade Paulista - UNIP, campi Norte e Vergueiro. 
comunicação \& educação • Ano XVI • número 2 • jul/dez 2011

Durante o curso sobre Direitos Humanos Human Rights Advocates Training Program, que frequentei nos Estados Unidos em 1997, tive contato com um projeto, à época nascente, de Gilberto Dimenstein, meu colega na Folha. Ele estava escrevendo o livro Aprendiz do Futuro, obra que serviu de base para o que viria a ser o Projeto Aprendiz, ainda hoje em plena atividade na cidade de São Paulo. O objetivo inicial do projeto foi oferecer um espaço virtual - já que a internet era ainda uma novidade no Brasil - em que os professores pudessem lidar com questões de cidadania usando a rede. Foi, senão o primeiro, um dos primeiros sites de educação do Brasil voltados para o professor da escola pública.

Fui convidado a contribuir com a fundação do projeto e, como jornalista de educação, tinha a importante função de levar informações sobre esse campo para os profissionais da área. Dentro do portal que estava sendo lançado, pensei em organizar um jornal semanal para que os dois milhões de professores do Brasil pudessem acompanhar o que de mais importante havia acontecido em educação naquele período.

O projeto foi lançado oficialmente em agosto de 1997, em parceria com uma escola particular e duas escolas públicas de São Paulo, cujos alunos se envolviam na produção de conteúdo. E o site logo exigiu espaço físico para o desenvolvimento de suas atividades. Em 1998, organizou-se a central de produção do Projeto Aprendiz - que se transformou em uma ONG ligada à educação e voltada a jovens da comunidade, vindos de várias escolas diferentes. Foi assim que um projeto que era de comunicação sobre educação foi se tornando um projeto de Educomunicação, já que os jovens estavam diretamente envolvidos na produção dessas informações, falando de comunicação sobre educação e de educação pela comunicação.

O próximo passo veio com a criação do curso Design Social, a partir da experiência bem-sucedida de produção, pelos jovens do projeto, de um site comemorativo dos 50 anos da Declaração dos Direitos Humanos. Em uma época em que a construção de sites era uma atividade restrita, o objetivo do curso foi ensiná-los a construir páginas na web para ONGs. Uma das coisas mais interessantes desse trabalho foi a liderança dos comunicadores, que se refletiria também em projetos futuros. O NCE - Núcleo de Comunicação e Educação e a Rede CEP, que criamos depois, tinham como objetivo inserir a comunicação na educação, além de sair dos modelos tradicionais de educação por disciplinas. $\mathrm{E}$ tudo isso acontecia, no caso do curso, por meio da confecção de um produto, que eram os sites.

A ideia deu frutos rapidamente. No início de 1999, quando o curso teve início, pedi demissão da Folha de S. Paulo e passei a gerir o Aprendiz, onde atuei como diretor até 2002. Gilberto era o grande empreendedor social, enquanto eu era o administrador, a pessoa que escrevia e organizava os projetos.

C\&E: Nesse momento você já se dedicava exclusivamente à Educomunicação?

Fernando Rossetti: Sim, porque, com a mudança de rumos profissionais, mais uma oportunidade de trabalho em Educomunicação apareceu. Saí da Folha na sexta-feira e, na segunda, já tinha o convite do Gilberto para dirigir 


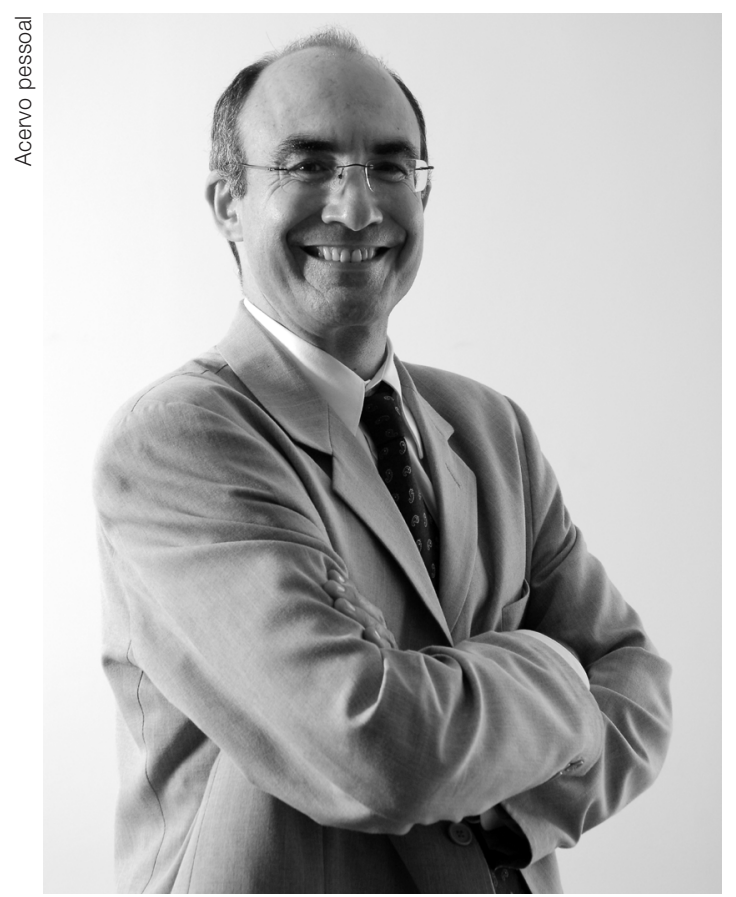

O cientista social Fernando Rossetti.

o Aprendiz e da Viviane Senna para trabalhar no Instituto Ayrton Senna. Combinei com os dois que me dividiria entre o Aprendiz e o Instituto, que já apoiava várias ONGs que atuavam nisso - inclusive o próprio Aprendiz -, e também queria consolidar o seu trabalho de Educação pela Comunicação. Era preciso criar uma política institucional para o Instituto nessa área. Surgiu então a Reducom - Rede de Educação pela Comunicação, focada na troca de experiências entre organizações e profissionais que faziam Educomunicação na sociedade civil.

Depois de um ano, voltei a me dedicar exclusivamente ao Projeto Aprendiz, onde fizemos muitas coisas diferentes envolvendo Educomunicação. Quando saí de lá, fui convidado pelo Unicef a montar um projeto para transformar ações pequenas de Educomunicação em políticas públicas. Nessa época, com a renda do Criança Esperança, o Unicef financiava várias ONGs que faziam Educomunicação, mas o trabalho era ainda bem pontual. Fui contratado, justamente, para olhar as ações já feitas e ver como isso poderia se transformar em política pública - o que é muito difícil.

\section{C\&E: Quais são os principais desafios enfrentados pela área de Educomu- nicação hoje?}

Fernando Rossetti: Eu saí da Folha numa época em que todos os jornais estavam em crise, como estão até hoje. Com esse cenário, a questão da Educomunicação se tornou importante - não só pela crise em si, mas porque a ideia anterior de educar para a comunicação, que era educar receptores, não fazia mais sentido. Hoje, todo mundo virou comunicador. Mudou o ambiente inteiro, todas as mediações comunicativas mudaram. O ecossistema comunicativo global, da humanidade, mudou.

A grande contradição da revolução nas tecnologias de comunicação e informação é que hoje existe uma segmentação gigante da mídia e, ao mesmo tempo, a concentração dos meios nas mãos de muito poucos. Atualmente, cinco grupos econômicos determinam $90 \%$ das informações que circulam no mundo, e que formam a cabeça de todos esses meninos que estão navegando e consumindo. E o que mais me impressiona, dentro desse quadro, é ver a falta de habilidade das escolas em lidar com a geração digital que se forma agora. As escolas ainda estão quilômetros atrás dos recursos de que os jovens dispõem. Todos estão aí, se relacionando por mil canais de comunicação, e a escola 
ainda acha que isso é perda de tempo. Se esse espaço é deixado vazio para as crianças e adolescentes, acabará sendo usado pela indústria do consumo. Mas, se temos atividades de comunicação dentro do espaço educacional, o educador vai pensar em como criar um uso mais cidadão desses meios.

\section{C\&E: Então, quem você acha que são os agentes de fortalecimento da Edu-} comunicação na sociedade hoje?

Fernando Rossetti: Acredito que essa seja um marcha irreversível - que, se não contar com a presença da escola, contará com a de outros atores, desde as empresas até as próprias ONGs, em um caminho de atuação baseado na experimentação. Quando começamos a trabalhar com Educomunicação, há sete ou oito anos, não havia nada sistematizado. Todos eram pioneiros. Isso aconteceu porque a Educom acompanha a revolução nas tecnologias da informação e comunicação. Se não fosse a entrada da internet, do celular e outros, não teríamos uma agenda tão forte de comunicação. E muito disso se deve também à iniciativa privada, que contribuiu para a inclusão digital no Brasil, porque o instrumento de maior acesso para isso são as lan houses. As pessoas mais pobres pagam para ir lá, mesmo que seja um real por hora - e não foi a escola que disponibilizou, nem o Estado, nem o investimento social privado. Foi a iniciativa privada.

Isso acaba influenciando a própria maneira como se vê a educação. Caricaturizando, temos dois extremos na sociedade brasileira. Um é o freireano, pelo qual se vê a educação como transmissão e geração de cultura, cidadania e justiça social. No outro extremo, temos a educação como geração de recursos humanos para o desenvolvimento econômico, geração de mão de obra qualificada para as empresas. Na realidade, ela é um pouco de cada uma dessas coisas, às vezes pendendo para um lado ou para outro. Mas, independentemente da sua ideologia, formou-se no imaginário social brasileiro a visão de que a educação é algo muito importante. Por isso, é um tema de consenso que merece a preocupação de todos os setores.

Ainda hoje, a maioria das pessoas que promove a Educom não está dentro do sistema oficial de educação - mas sim na sociedade civil organizada, universidades e ONGs. Considero este um movimento que surge de fora do mundo da escola e vai para dentro da educação. Nesse sentido, acredito que o NCE é o grande pioneiro em termos universitários e acadêmicos, por entrar na escola e não ter medo de experimentar. Faço uma crítica geral à universidade por não dar maior destaque às atividades de extensão, envolvendo o trabalho nas comunidades e escolas em seu modelo de atuação - que normalmente é forte em ensino e pesquisa. É curioso, por outro lado, que o NCE parta de uma Escola de Comunicações e não possua um diálogo mais forte com escolas de Educação. Acredito que a Escola de Educação tenha, ainda, certa dificuldade de interlocução.

Aos poucos, porém, o próprio setor educacional tem se conscientizado da importância de acompanhar a evolução da educação, do ponto de vista dos jovens - embora essa seja uma lenta caminhada. $\mathrm{O}$ modelo tradicional que temos 
de educação é o modelo da linha de montagem: eu coloco uma coisa e espero um certo output, cujo resultado é medido depois que o processo terminou. Mas, quando se faz Educom, até mesmo os instrumentos de aferição de resultados são frágeis. Em um dos meus livros, comento que o sistema de correção na língua portuguesa, por exemplo, é muito claro para o professor: ele corrige em vermelho o que está errado e confirma o que está certo. Já num fanzine, por exemplo, o uso da língua portuguesa é completamente diferente, o que é muito difícil para o educador tradicional entender. A maneira como a escola está organizada, hoje, é um problema para projetos de Educomunicação - que pressupõem mais de um professor por sala de aula, períodos que não sejam o de 50 minutos e outras coisas que a escola não está pronta para incorporar. Então, é mais fácil criar massa crítica, não necessariamente fora da escola, mas fora da grade curricular, usando a Educom como atividade complementar à escola e multiplicando experiências.

C\&E: Como você vê a aprovação da Licenciatura em Educomunicação na ECA-USP e os desdobramentos disso para a educação e a pesquisa?

Fernando Rossetti: A aprovação de uma licenciatura em educomunicação é mais um passo na institucionalização e entrada formal desta disciplina na formação de todas as crianças e jovens brasileiros. Até agora, os passos que o movimento da educomunicação vinha dando eram de aproximação cada vez maior das políticas públicas de educação, a abertura de uma licenciatura nessa área, ainda mais na ECA/USP, é um salto para o movimento, fortalecendo o conjunto das organizações, governamentais ou não, que trabalham com educomunicação.

C\&E: E para os jovens, quais são os recursos, ferramentas e abordagens que fazem a diferença no processo de aprendizado?

Fernando Rossetti: A primeira coisa que o jovem se pergunta é se aquilo que ele produz serve para alguma coisa. Na educação tradicional, tudo que se aprende serve para a prova que se vai fazer, ou então a importância daquele conteúdo só será percebida no futuro. Na Educom, a sua produção - seja um jornal, um site ou um programa de rádio - não vai ficar parada na estante. Ela tem relação com outras pessoas, tem relevância social. Essa atividade ajuda os jovens a darem um sentido positivo para a vida, usando a comunicação como instrumento de intervenção na realidade, de geração de identidade positiva dentro da sociedade. Fazendo um jornal e se relacionando com a comunidade, você pode até mudar um ecossistema comunicativo inicialmente negativo e, consequentemente, o sentido que as próprias pessoas dão para a vida. O segundo ponto positivo é que não lidamos mais com o conhecimento dividido em compartimentos: para fazer um jornal, são necessários todos os conhecimentos juntos.

Essa descompartimentalização, característica da Educomunicação, é uma vantagem para o profissional de comunicação dentro do trabalho educacional. O comunicador, como se costuma dizer, é um "especialista em generalidades". 
comunicação \& educação • Ano XVI • número 2 • jul/dez 2011

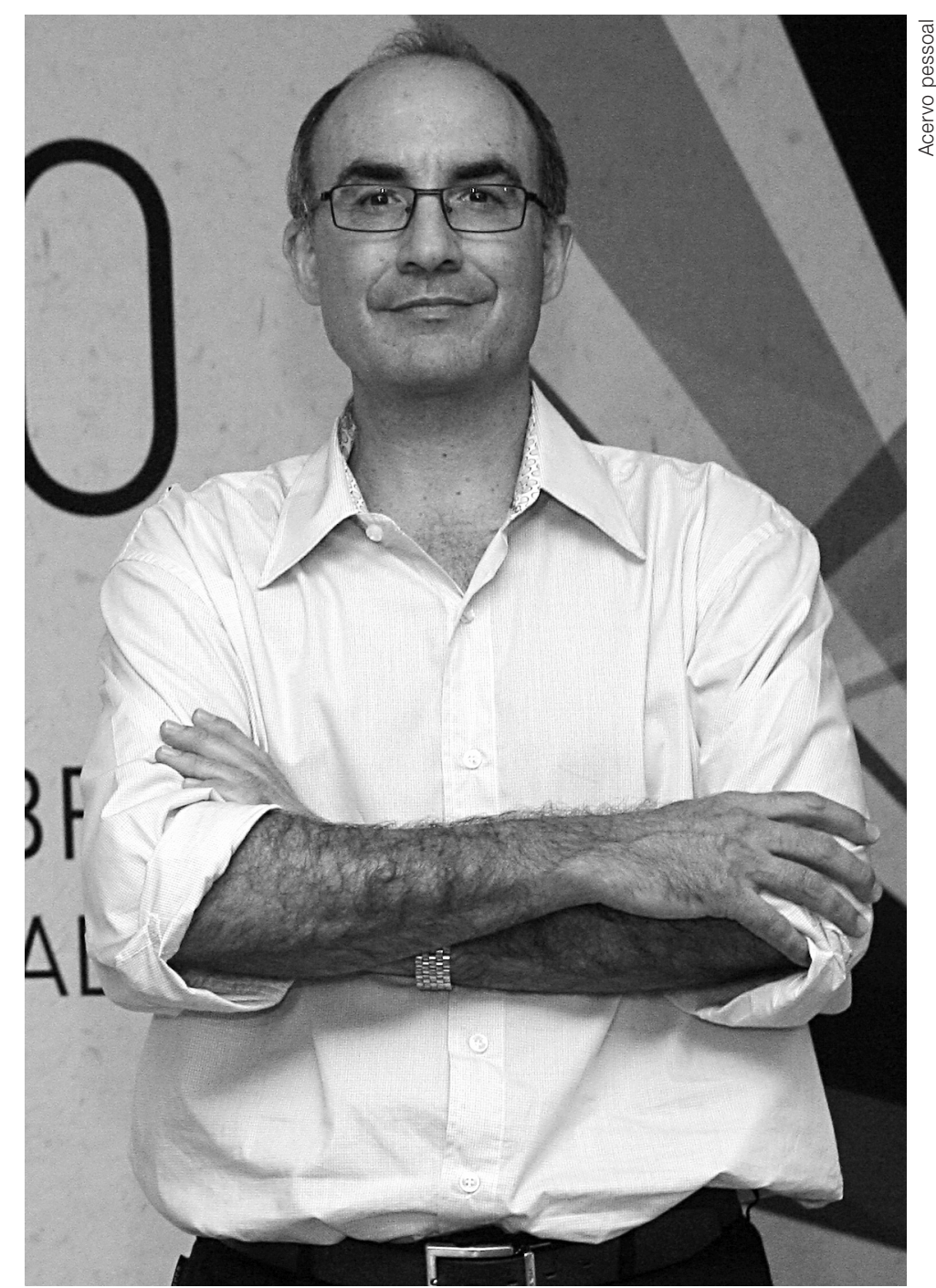

Fernando Rossetti: é preciso compreender a sociedade para escrever sobre a sociedade. Hoje em dia o comunicador só tem formação nos meios, nas formas, e não nos conteúdos.

Transitando entre vários temas, seu trabalho é, naturalmente, interdisciplinar. Acho, por outro lado, que uma das falhas na formação de comunicadores é justamente a falta de profundidade em certos assuntos - seria preciso entender mais sobre política, antropologia, economia. É preciso compreender a sociedade para escrever sobre a sociedade. Hoje em dia o comunicador só tem formação nos meios, nas formas, e não nos conteúdos.

C\&E: As diferentes características das áreas de comunicação e educação não poderiam se tornar, então, elementos complementares no trabalho conjunto entre ambas?

Fernando Rossetti: Acho que a Educom tem um grande papel a prestar com relação às questões do uso dos meios e do consumo. O princípio da rede CEP, por exemplo, é o de oferecer a toda criança na formação básica o acesso à produção de comunicação, como um instrumento de cidadania. Mas a criança 
não aprende isso sozinha, precisa ter um educador que crie as condições de produção e possa inserir os processos comunicativos na escola - mesmo que não seja necessariamente um Educomunicador, onde ainda não houver estrutura da escola para mantê-lo.

C\&E: Como você vê as iniciativas de transformar a área em política pública?

Fernando Rossetti: Nesse sentido, considero o reconhecimento da área de Educomunicação pelo Ministério da Educação (MEC) uma evolução muito importante, resultado da mobilização de diversas organizações independentes para colocar esse tema na agenda. A conquista no nível das políticas públicas significa que a Educomunicação se tornou uma das áreas de oferta dentro do Guia de Tecnologias Educacionais, criado pelo MEC para os municípios aos quais repassa dinheiro para capacitação. É como o guia de livros didáticos: o diretor recebe o livro e escolhe quais cursos quer fazer; são oferecidos por ONGs ou universidades. Considero este guia o maior avanço no nível das políticas públicas, porque oferece aos sistemas municipais alternativas de formação. Não acredito em impor conteúdos para as escolas, até mesmo porque muita coisa já é imposta a elas. E quando as redes pedem a Educomunicação, ela começa a se transformar em política pública. Mas ainda acho que, pela própria descontinuidade e fragilidade das políticas públicas de educação no Brasil, é preciso ter um setor independente trabalhando com isso.

C\&E: Como, então, vencer o desafio da implantação da Educom nas escolas?

Fernando Rossetti: Acho que deve ser sob estratégias diferenciadas. O Brasil é muito grande, tem 200 mil escolas. Então, na Amazônia ela vai funcionar de um jeito, no interior de outro, para os índios de uma determinada comunidade de outro. A estratégia é essa da aliança, de ter uma universidade por perto, as escolas pensando em como melhorar, os comunicadores e uma massa crítica entre esses atores, especialmente nas comunidades menores. $\mathrm{O}$ MEC, por exemplo, faz seu guia de tecnologias educacionais baseado no projeto político-pedagógico de cada município - a necessidade maior de cada um pode ser informática, comunicação ou outras, mas sempre é trabalhada em parceria com organizações que atuem em cada área.

C\&E: Você desenvolve atualmente um trabalho voltado ao setor empresarial. Ainda assim, aplica a Educomunicação em seu dia a dia?

Fernando Rossetti: O Gife tem como missão aperfeiçoar e difundir conceitos e práticas do uso de recursos privados para o desenvolvimento do bem comum. Em outras palavras, auxilia os investidores privados a melhorar o jeito pelo qual investem socialmente - seja em educação, cultura, juventude, meio ambiente, direitos humanos ou outras causas. Quando vim para o Gife, era uma área totalmente nova para mim, embora seja também um trabalho de fortalecimento da sociedade civil, ainda que sem interface direta.

No Brasil, como a maioria dos incentivos fiscais vão para as grandes empresas, elas se tornam as principais investidoras em causas ligadas à sociedade 
comunicação \& educação • Ano XVI • número 2 • jul/dez 2011

civil brasileira - diferente do que ocorre no hemisfério norte, onde os indivíduos doam muito dinheiro e há diversos formatos de investimento social. A pergunta que eu faço, para os associados do Gife, é: já que você quer fazer o bem com o seu dinheiro, seja você uma pessoa, uma empresa ou uma família, como fazer o bem de forma benfeita? Nesse sentido, ajudo a criar ambientes de aprendizagem para que eles possam fazer isso. Os associados do Gife são apenas 131, mas representam os maiores do Brasil e mostram as tendências nesse setor - investindo juntos 2 bilhões de reais em projetos sociais, sendo mais de $80 \%$ deles em educação. Dessa forma, meu trabalho de hoje é muito complementar ao meu histórico, já que atuo num campo político onde há muita comunicação. Eu diria que a formação em Educomunicação dá chão para qualquer coisa que você queira fazer. Tudo que eu sei sobre educação, comunicação e trabalho com crianças e jovens, é útil aqui. De uma forma ou de outra, acho que irei usar esses conceitos a vida toda. 